\title{
Young and Powerful Characters: An Analysis of Illuminati in Manga
}

\author{
Diana Budi Darma \\ English Department \\ Universitas Negeri Surabaya \\ Surabaya, Indonesia \\ dianabudi@unesa.ac.id
}

\author{
Mamik Tri Wedawati \\ English Department \\ Universitas Negeri Surabaya \\ Surabaya, Indonesia \\ mamikwedawati@unesa.ac.id
}

\begin{abstract}
Man power in literary work has become a popular topic nowadays. One of its implications is the concept of illuminati. This concept conveys indifference between logic and faith, which develop in an issue of dominance in the existence of manhood. As a contemporary concept it is also a controversial issue for certain level of readers. The obstacles are matters that relates to the ideology intention in a text, which produces similar interpretations. This phenomenon was identified in comics that flourished after Manga was introduced. Furthermore, these types of texts are preferable in society because they expose more of the illustrations in fixating meanings. To approach this analysis ecocriticism was applied to reveal obvious characteristics of the concept. There were two analyses that were conduct, which are identifying logical dominance and grouping the pictures into definite concepts.
\end{abstract}

\section{Keywords: characters, Illuminati, Manga, literary work}

\section{INTRODUCTION}

Porrovecchio stated the existence of Manga was not only representing Japan's spiritual and religiosity but more of transition of their concepts, which are adjusted in western society. He focused on the transition of picture books that formerly explored classical beliefs and continuously empowered new western concepts for the development of Manga. Historically, underwent a radical movement from a preserved society into a liberal environment, these texts were a vehicle for writers' aspirations [1].

Japanese Youth Movement was revolved in the era of the culture industries in 1970s stated Kinsell [2]. The revelation was primary to provoke economical issue, which had become iconic of text's illustration and narration. Furthermore, the existence of characters was to convince readers of youth expectation from the nation. Therefore, content of the texts focus mostly on the power of a young human characters.

Apparently, a combination of religiosity and liberal were introduced in the main character, which provoked the dominance of mankind. Symbols of these characters are basically of youth, power and man. Inserting values were performed by practicing visual works, which were able to give concrete messages. To show the obviousness, meanings were constructed through battles that consist of Gods and mystical powers. Therefore, classical and modern meanings were included in the texts [3].

Insofar, religion and mankind have positioned equally in the plot, which connotes varied interpretations of the readers. Characters such as Jesus and Guru were found in comics Guru Nanak and did not result in contradictive situation because of its popularity. Artists were confident to create a powerful character that resembled "God".

A religious text is a synonym of Japanese text in its popular registration. Themes that are recognized in the text to preserve values in classic Japanese believes and also to combine other values such as western ideas in supernatural elements. Therefore, pictures that were included in Manga were identified as delivering sacred messages, whereas, presently most of the texts are consumed for more economical purposes.

The idea that is altered in contemporary texts is stressing on a transition of the concept of God. Previously, it is a define understanding for believers but illustrators give extra meanings of each character that was introduced. The existences of these characters have been accepted by readers and society as part of their perspectives. Discussions and researches were eager to develop these texts not only in writings but also in visual productions [4].

Interactions are grouped into two characteristics, which are mankind and Gods. They are developed to define their relationship rather than focusing on religiosity elements. Events, which consist of battles and entitling Death Note are the main purpose of the plot. By creating them, conflicts are builds through the role of God and human being. Furthermore, inherits a power that was given as a destined faith. Mankind is described to have prominent obligation for the existence of the world.

This identified matter is a contemporary idea, which elaborates dominance in mankind. Power that was descended is a symbol of highest position as of a creator or God. Furthermore, actions are developed to build a strong foundation of this idea. They are in forms such as strength, weapons and spiritual attitudes. Therefore, problems that emerged contain man's roles and how they were defined. 
In line with the discussion above, an approach was chosen, which is Illuminati. This is a concept that was introduced by Bavarian Illuminati and appeared term secret organization. Literary works have introduced this concept since 18th century by a novel entitled Frankenstein [5]. To be able to hold a perfect project, the creator had used all electricity around her neighborhood, which was a width area of land and residence. From these events, the atmosphere has changed and caused controversial reaction toward the readers. Previously, this was approached by supernatural elements but 21 st century setting would be interest in dominance.

Furthermore, the analysis was done through close reading of certain episodes in each comics to sort data from, hundreds of chapters. These data were categorized through identifying illustrations and expressions. The main focus was interpreting pictures and sketches of main characters because visual data had more portion rather than written form. Furthermore, their physical appearances and behaviors were collected primarly because their were pictured repetively. They were also given additional anctuation to enrich the sketches. Expressions, which consist of sounds and sentences, were supporting details in the analysis. Afterward, sorted meanings were analyzed and concluded.

\section{ILLUMINATI}

Bavarian Illuminati was an ideology that was introduced by Adam Weishoupt in the field of law [5]. It was conceptualizing freedom through human rights and perspectives. The essense of this concept was man must use logic in dealing with matters ${ }^{2}$, which was a contradictive issue in the $18^{\text {th }}$ century [6]. Government, which was a party that handles political matters, was opposed by a radical group. This situation had formed political societies, conspiracies, and secret associations. The opponent offers a new concept in ruling the nation or a new world order. Human rights were interpreted in different perspective in gaining freedom. Authorities preffered traditional values and other offered man power. The second party continues to evolve and gave stronger ground in $20^{\text {th }}$ century [6]. In this era, mankind was a power that took serious concern on law that was not applied for justice. This statement declared dominance in mankind and gave signature in United States democracy.

The present concept of Illuminati did not differ from Bavarian era. United Stated, freedom has been an identity since the nation was built [5]. It has united them to protect each freedom against enemies that were taken away citizen's rights. Insofar, government and other influential parties have grown firmly in this character. American writers were eager to picture society in urban settings. Some were developing main characters as free thinkers. This situation is a reaction toward a traumatic experience that made most of European citizen migrated to an empty continent [5]. Human rights are still their foundation and wider followers were identified in building the new system. Therefore, Illuminati is able to be understood widely.

Texts in protesting traditional values, is a significant step. People were able to create a new version of bible that named based on their act. They were against social status that were politically made to control and gain power over them. Afterward a protest was declared to defend their opinions. This was also implied in government system, which is liberal democracy and since then continue to grow prominently in the future. The decision was based on a brainstorm of many nations, which constructed their identity. This rational process in giving decision had made a strong characteristic in the setting. At the end of the century, this event had been a source for writers in producing similar themes, which had become a literary trend.

Presently, Illuminati is still a secret organization or paranoid style. As a melting pot, reasoning was a suitable way in making decision [7]. After 400 years of a nation, it is still firm in defending individual quality and aspirations. Furthermore, super heros that were introduced through comics such as Superman , Batman or Hulk were examples of popular text that had fanatic readers [8]. It continued to develop until it had a perfect vehicle in its spreading. Among many books that consisted similar themes, picture books were favorable.

Comic was one of a convenient media to express controversial realities because of entertaining element. Furthermore, vivid pictures and affirmative expressions have contributed concrete messages for readers. One example that visual communication is preferred compare to written from is the production amount of publishing new episodes in every title. Presently, Manga, a Japanese version of picture books, is popular in young generation. It has caused addiction in the habit of reading and changed their life style.

Obscene illustrations and vulgar expressions have mesmerized them into a reality that was opposite with their main surroundings. This controversial thoughts have represents vast and dynamic culture of young generation aspirations, which tend to be more direct as a rebellious act toward the era.

For almost 20 decades, the collaboration between west and asia has been established through comic books. Messages were constructed on both backgrounds and conveyed with direct intentions. Furthermore, readers were able to enjoy and take granted of these books because of acknowledging the similar intentions.

\section{MethodOLOGY}

In line with the discussion above, an approach was chosen, which is Illuminati. Nevertheless, its common meaning was people's attitude toward matters and continued to develop. Historically, Bavarian Illuminati, which was triggered by Industrial revolution, introduced a contradictive perception on civic and religiousity [9]. Waterman contemplated through American novels and citizens reactions toward a new world, which was basically a branch of the concept that emphasized on reasoning.

Logical and reasoning were greatly a popular approach in understanding texts. Varied of meanings were interpreted through productive works that were mostly described in visual work. Mousavi illustrated the functioned of anime to scholar readers.. He elaborated the simplisity of delivering influential 
contents for Iran readers. Furthermore, Laplante emphasized that picture books were more concerned on symbols. This preferred sophisticated treatment to dismantle meanings.

Natsume explained expressions were a unity of the sketches. He defines that letter were enabled to be interpreted separately for the illustrations. Words that formated in bubbles were supporting a completetion in each characters of Manga. Schutz was able to enrich the coding in expressions. He elaborates that interpreting a text would required a depth understanding of both points of views, which were author's and reader's. Moreover, Cohn had mentioned Manga was a representative of nature in creating its characters. Communication that was build expressed, more or likely mystical elements. This relates with powerful hero who possessed incredible energy.

To analyze youth and power in characters, there were two aspects that were processed, which are illustration d expressions. Raw data were collected by selecting Manga that identified similar in the sketches. Continuously, this was applied by close reading of certain episodes in each comics to sort data from hundreds of chapters. They were chosen by pictures that represent youth and power. Moreover, they occured but with similar characteristics. Afterward, expressions, which consist of sounds and words, were supporting details to explain the behaviour and personality of the character. Finally, all these information were interpreted and concluded.

\section{DISCUSSION}

Death Note and Berserk are two Japanese comics (Manga) that build characters through two prominent qualities, which are power and youth [8]. Authors were exploring minorities' perceptions in elaborating evil and mysticism in a modern environment. This topic made picture book a popular plot. Similar with American comics, main characters were not human. Their qualities were a symbol of Hercules, who possessed beyond the quality of a human being. Dominance and freedom were two elements that were elaborated through the episodes.

This type of character would consider rational and reasoning attitudes because applying stereotyped versions would result in unanswered questions. This also was a sinful act when Frankenstein was created and it became alive. Giving soul in a unliving body would not be accepted in religios perception. Therefore, only logical understanding was able to accept human being similar to a creator.

Altering logical events in both comics were considered a main issue in developing the plot. Strong authority was constructed to define main characters, which supporting matters that were ensembling details in its elements carried one clear picture of man's power toward the world. First impression that was emphasized was sex. The main characters hade both man a woman features. It was constructed since the beginning of the story. They were reborn into strong and different figures, which were instinctly influenced by society's perspective. A marginal community in Japan, which was seen in several groups such as in America and Japan, was known for its values. They had not only exposed a figure but also introduce their environments.

Characters were created with specific figures and features. Most of them are exposing hard figure in a body that was shaped by life experiences. Muscular, which were perfectly built were found on places that were supposedly found. Furthermore, they were imprinted as battles and hardships in their past lives. Parts of lives that were clearly created to push the evil behaviors and rebellious acts are forms of completion[10].

Existence of powerful man was initiated when missionaries were possessing mystical energy in protecting their predecessors. They were given tasks to warn others through prophecies and wisdom. At the end of 20th century, the characteristics did not change. Human being was still a source of information and a center of transformation. This fact was seen through vulgar and controversial descriptions. Characters were given more decorations both in behavior and physical appearance.

Insofar, these representations were the foundation of development of the plot and comics. A symbol of strength and order continued to expand through history and future expectations. Ideally, religiosity had been valued, which were inherited and preserved to maintain manhood. Furthermore, the character must resemble expectation of life, even though, taken from low class society, which consisted of contradictory values[4].

Meanwhile, revealing contemporary values would be accurate by utilizing settings. This element had two types, which were time and place. They were also describing mystical atmosphere and obscene events. Time wass mostly in young age and includes past and present periods. Both comics had started with an unlucky situation, which was possible to resemble unidentified status class. This class society wais similar with secret organization, which was a popular issue in politic.

Japan, which believed in nature, most of the actions were referring to their interaction with their environments. This was similar with American society, which was an exodus of disagreements with religious institution. Results of pressure from authorities caused a radical change in interpreting life.

Historically, classic comics were describing religiosity that human being had overcome to convey traditional values. Presently, these texts are drastically changed into a different environment and values. Illustrations were simple and ordinary of common Japanese citizens. On the other side, contemporary pictures did not represent common people but more of details that were not found in the former figures.

Continuously, logical explanations of each event were elaborated through chronological time and place that were decisions made by a certain message from mischievous intentions. Commonly, understanding a controversial reality would need a process that contains pros and cons. These reactions were rich sources to inspire authors and writers in constructing a reality. Therefore, illustrations that were produced in hundreds of repetitions by using a similar hero would be acceptable for fanatic readers. 
Tone is not written down explicitly but gives a strong beat in each event. Dark and solemn sketches with less verbal explanation from characters, which focus on the physical appearance of both main characters and readers interpretations, would conclude into similar perceptions. Thus, this atmosphere supported a great portion in the development of characters.

As an isolated and rage picture do not initiate emotive stereotype of a human being. Anger and disappointments were images that were created not only in faces but also in gestures. They were easily communicated because of factual events that were taken in the environments. The other atmosphere that were identified was producing a counter act, which was built secretly or paranoid act, which were concetualized by critics.

This trend had mixed opposite values, which originately explored history of Asian and Western facts. Formerly, Asian culture was described as a mystical and preserved society and, on the other hand, Western culture was more of liberal community. Nowadays, the differentiation was a new horrizon for man and its ideology. Values were more analyzed through reasoning. Religions were appreciated as cultural events that concerns on customs and cebrations. Discriminatios were found in politics but not in social or individual negative accusations.

Manga was a unity of transnational texts and representatios. Its picture messages were transferred into universal values and had obviously adopted modern inspirations. What once was a strict illogical events were now of reasoning combats and man's decisions. Therefore, a stricter and sacred source of picture book is now become a common aspiration of marginalized community [2].

Society reacted firmly toward these types of texts because they do not preserve local values. Illustrations that were decent and proper were exchange into of obscene realm. This realms are likely similar to an exclusive community that was known in the 19 century as a new world order. They were revealing an underground movement that was not in line with traditional values. This was a great attention of young generation who felt that traditional culture was captivating them. Japanese government did not openly disagree in their actions but took it as a part of the development.

The acceptance of contemporary idea, which consisted of Illuminati features, played a role in Japanese modernism. It was given a role to compensate opinions that were less accommodated in political environment. Its growth had given space to advertise and promote its existence. It was a form of admission, which was declared gradually by society's criticism. Moreover, it also created curiosity and addiction for readers.

This concept of men and logic continued to represent opposite perspective widely. A form of rebellious act of teenagers in picture books was convinced a media for exposing them but, in fact, fanatic readers were summing up in great quantity. Unconsciously, it gave a solid domain in exploring essential values and a root to stand.
Evidence of its enrichment of sources was piled through episodes that were created. They were a miniatur of a domain that consisted of freedom and its interpretations. Characters that were designed young and powerful had been prominently a tool to describe authority and world order. Insofar, illustration had not only a picture of a creature but also a unification understanding of messages that were conveyed concretely.

A visual character become more clear when suitable expressions were given. Both main characters were not communicating through lengthy words but more of restricted chosen words. These limitation built sentences that produced meanings direct to their purposes. This straight forward intention was a concept of communication how to inform others in a firm interpretation. Therefore, verbal expressions were levelled as a secondary source in these comics. Figure 1 shoeds how the Manga gave more impact from picture than words. However, words emphasized the purpose of the character.

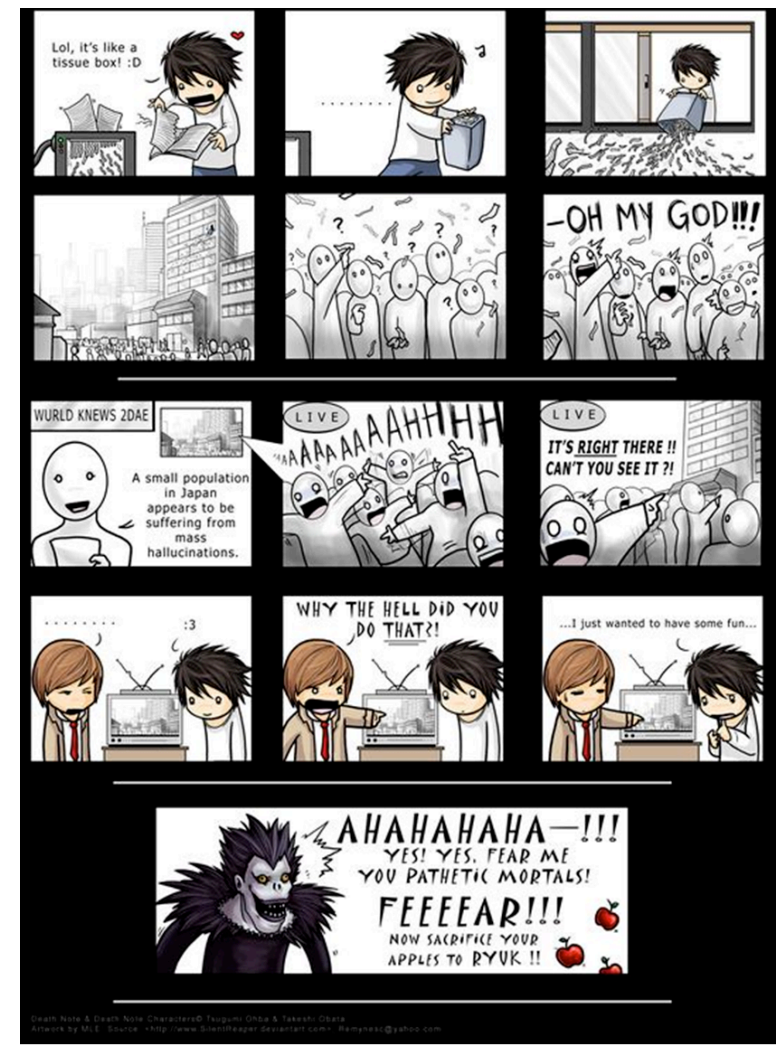

Fig. 1.

Nevertheless, meanings that are produced in different interpretations were aiding the existance of intended charecters and guiding confirmations for readers. They were implementing details in building a character where a unification of Western and Asian figures that were discovered.. Furthermore, English as the chosen language in delivering ideas had an international standard.

Verbal expressions that had been chosen were different with books that utilized narration. Limited vocabularies were 
fact of direct instructions and vulgar instinct in ruling each plot. Moreover, deep contemplation of main characters were influencing other elements in constructing other events. Therefore communication that was practice in the setting was less interacted through written expressions.

Expressions that had been categorized were imperative and obedient messages. In practice, stresses to show dominance were often labelled in main characters to divine power that was given to them. Obedient sentences were opposite expressions that produced more sentences to choose defensive expressions. The comparison expressions were data itself to reveal its important role in developing meanings.

Meanwhile, other expressions were less analyzed because of unnecessary matters. Sounds of emotions were expressed in most of its pages to describe battles, defeatism, victory, pain, etc. These data had similar role in verbal expressions because readers would understand the nuance that the writer intended to build.

\section{CONCLUSION}

Dominant characters were created by the author to reveal ideal expectations of man dealing problematic matters in daily life. They were transformed into young and powerful illustrations that were completed through related expressions such as firm and preserve. Transformed ability from mystical to rational, which indicated through a central figure in the text, controls other characters and built a powerful atmosphere. Therefore, both main characters Light Yagami and Guts were strongly attached with all these decorations.

\section{REFERENCES}

[1] A. Porrovecchio, "Manga, Wuxia and (New) Religious Syncretisms: the Orientalization of the Western Imaginary, from Osamu Tezuka to Contemporary Oriental Disciplines," J. Relig. Media Digit. Cult., vol. 2, no. 2, 2013.

[2] S. Kinsella, "Japanese Subculture in the 1990s: Otaku and the Amateur Manga Movement," J. Jpn. Stud., vol. 24, no. 2, pp. 289-316, 1998.

[3] L. C. Shah, The Secret Goals of United Nations New World Order andTtheir Ultimate Goal to Rule as Governement of The World C-1, Ceebros Castle, 15, Valmiki Street, T. Nagar, Chennai 600017 India. C1, Ceebros Castle, 15, Valmiki Street, T. Nagar, Chennai 600017 India.

[4] B. Wilson, "Becoming Japanese: Manga, Children's Drawing and The Construction of National Character," pp. 43-47.

[5] B. Waterman, "The Bavarian Illuminati, the Early American Novel, and Histories of the Public Sphere," William Mary Quarterly, Third Ser., vol. 62 , no. 1, pp. 9-30, 2005.

[6] E. Turney, "The Illuminati Almost Certaintly Subverted the United States of America."

[7] D. Livingston, "Terrorism and The Illuminati:A Three Thousand Year History," BookSurge LLC.An Amazon.com company.7290 B Investment Drive Charleston, SC 29418.

[8] D. Shamoon, "The Yōkai in the Database Supernatural Creatures and Folklore in Manga and Anime," Marvels \& Tales, vol. 2, pp. 276-289, 2013.

[9] C. C. Bradshaw, "The New England Illuminati: Conspiracy and Causality in Charles Brockden Brown's 'Wieland,"' New Engl. Q., vol. 76, no. 3, pp. 356-377, 2003.

[10] L. Bucher, katherine T., and Manning, Bringing Graphic Novels into a School's Curriculum. virginia: The Cleaning House., 2004. 